\title{
POR UMA NOVA DEFINIÇÃO DA VERDADE*
}

Alain Badiou

Alain Badiou
Professor emérito
do Departamento
de Filosofia da
École Normale
Supérieure, na qual
fundou o Centre
International
d'Étude de la
Philosophie
Française
Contemporaine,
em 2002.
Tradução
Luiz Paulo Leitão
Martins
Doutorando pelo
Programa de
Pós-Graduação em
Teoria Psicanalítica
da UFRJ. Bolsista da
Capes.

RESUMO: Este artigo sintetiza o projeto filosófico de Alain Badiou, com base na divisão de sua principal obra em três tomos. Em $\mathrm{O}$ ser e 0 acontecimento, o autor abordou a questão da verdade em relação ao ser: uma teoria do ser como multiplicidade genérica. Em Lógicas dos mundos, a mesma questão foi pensada do ponto de vista do aparecer: uma lógica de incorporação das verdades, segundo a sua distribuição local em diferentes mundos. Em $A$ imanência das verdades, livro a ser publicado, Badiou retomará o ser e o aparecer do ponto de vista de uma teoria das verdades: uma dialética entre finitude e infinitude, um encontro da filosofia com a vida.

Palavras-chave: Verdade, sujeito, ser, filosofia, vida verdadeira.

ABSTRACT: Towards a new definition of truth. This article summarizes the philosophical project of Alain Badiou based on the division of his masterwork in three volumes. In Being and Event, the author approached the question of truth in relation to the being: a theory of the being as generic multiplicity. In Logics of Worlds, the same question was thought from the viewpoint of apparition: a logical of the incorporation of truths, according to its local distribution in different worlds. In The Immanence of Truth, a book to be published, Badiou will retake the being and the apparition from the perspective of a theory of the truths: a dialectics between finitude and infinitude, an encounter of philosophy and life.

Keywords: Truth, subject, being, philosophy, true life.

DOI - http://dx.doi.org/10.1590/S1516-14982015000200001

\footnotetext{
* Este texto inédito é tradução da conferência O que é uma verdade?, ministrada por Alain Badiou na International Conference on Alain Badiou's Fuvre, na cidade de Praga, República Tcheca, em 2014. A transcrição do original em francês nos foi gentilmente oferecida pelo próprio Badiou, a quem agradecemos o interesse e a autorização para sua publicação em português.
} 
$\mathrm{T}$ odo o meu trabalho filosófico consiste em propor uma nova definição do que é uma verdade e em tirar conclusões disso em relação à nossa existência como sujeitos. Coloquemos as coisas em perspectiva.

O ser e 0 acontecimento (BADIOU, 1988) pode ser considerado como a primeira parte de uma construção em diversos tempos, parte que concerne sobretudo à questão do ser. O que seria o ser, o “ser enquanto ser”, como o nomeia Aristóteles? Quais são as vias e os meios de conhecê-lo?

Minha proposição ontológica é que o ser enquanto ser é uma multiplicidade pura, quer dizer, uma multiplicidade não composta por átomos. O ser é evidentemente composto por elementos, mas esses elementos são multiplicidades, as quais são elas mesmas compostas por multiplicidades. Chega-se, no entanto, a um ponto de interrupção, que não é de modo algum o Um - o Um seria necessariamente um átomo — mas o vazio. Eis aí minha proposição do ser. Quanto ao conhecimento do ser, minha proposta é identificar a ontologia - o discurso sobre o ser — à matemática, considerada ela mesma como ciência do múltiplo puro, do múltiplo "sem qualidades” e sem Um.

Aliás, O ser e o acontecimento (BADIOU, 1988) desenvolve, como contraponto, uma teoria das verdades que consiste numa teoria formal das verdades: as verdades são, como todas as coisas, multiplicidades. A particularidade delas é que dependem de um acontecimento, que é uma multiplicidade evanescente, multiplicidade que não encontra, na situação em que tem lugar, fundamento algum. Uma verdade é uma multiplicidade que se compõe a partir das consequências de um acontecimento, e que é, assim, sustentada por um ser infundado. Trata-se, portanto, de saber de que tipo é essa multiplicidade, paradoxal e sobretudo rara, que se chamará verdade. Logo, o livro trata, ao mesmo tempo, de uma teoria do ser e de uma teoria das verdades; tudo isso no quadro geral de uma teoria do múltiplo puro, a qual é, de tempos em tempos, afetada por um surgir infundado que eu chamo de acontecimento.

A segunda parte dessa construção, Lógicas dos mundos (BADIOU, 2006), dedica-se à questão do aparecer. Trata-se de uma teoria do que, do ser, aparece em determinados mundos e forma as relações entre os objetos desses mundos. Proponho dizer que essa parte da construção do conjunto é uma lógica. Trata-se de uma lógica, já que ela concerne não mais à composição do que é, mas às relações que se tecem entre todas as coisas que aparecem localmente nos mundos. Em suma, depois de uma teoria do ser, uma teoria do ser-aí - para empregar uma expressão próxima àquela de Hegel — isto é, do ser tal qual ele é alocado e disposto nas relações de um mundo singular.

Em Lógicas dos mundos (BADIOU, 2006), a questão da verdade é evidentemente retomada. O ser e 0 acontecimento (BADIOU, 1988) tratava do ser das verdades enquanto multiplicidades especiais, multiplicidades que podem ter valor universal, 
aquilo que, depois do matemático Paul Cohen, eu chamei de multiplicidades genéricas. Com Lógicas dos mundos (BADIOU, 2006), entramos na questão dos corpos reais, da lógica de suas relações e, em particular, na questão do aparecer das verdades. Se tudo o que aparece no mundo é um corpo, é preciso abordar a questão do corpo de uma verdade. Esse segundo tomo tem, portanto, de maneira ampla, por finalidade uma teoria dos corpos que também possa ser uma teoria dos corpos de verdade, assim como o primeiro tomo tem por finalidade uma teoria das multiplicidades que também possa ser uma teoria das verdades enquanto multiplicidades: as multiplicidades genéricas.

O projeto do terceiro tomo é examinar as coisas e, portanto, o ser e o aparecer, do ponto de vista das verdades. O primeiro tomo pergunta: o que são as verdades em relação ao ser? O segundo: o que são as verdades em relação ao aparecer? O terceiro perguntará: o que é o ser e o aparecer, do ponto de vista das verdades? Assim, terei percorrido todo o contorno da questão.

O problema é que a chegada a esse terceiro tempo supõe longos desvios e questões muito difíceis.

Uma verdade, do ponto de vista humano, do ponto de vista antropológico, é composta por incorporações individuais nos mais vastos conjuntos. Eu gostaria, portanto, de saber como se apresentam o mundo e os indivíduos do mundo, como eles são dispostos, quando passamos a examiná-los no interior dos próprios processos das verdades. É uma questão que inverte de alguma maneira a perspectiva dos dois primeiros volumes. Perguntava-se o que eram as verdades do ponto de vista do ser e do ponto de vista do mundo, pergunta-se agora o que são o ser e o mundo do ponto de vista das verdades. Logo, nós nos encontramos diante de problemas de escala: as verdades, como o ser, são, em essência, infinitas, já os corpos, tal qual aparecem nos mundos, parecem irremediavelmente marcados de finitude. Como apresentar, nos dias de hoje, essa dialética do finito e do infinito que atormenta a filosofia desde, em todo caso, a era moderna, desde Descartes, para o qual, enigmaticamente, o infinito era uma ideia "mais clara" que aquela do finito?

Encontram-se, naturalmente, esboços dessa dificuldade nas duas obras anteriores. O ser e 0 acontecimento (BADIOU, 1988), em particular, contém uma teoria bastante complicada do efeito de retorno das verdades infinitas sobre o mundo, onde, depois do acontecimento que as fez nascer, elas se desenvolveram. Esse efeito reside na figura do saber. A tese é que se chamará saber, novo saber, criação de um saber, a forma pela qual uma verdade ilumina de maneira diferente a situação ontológica. É como em Platão: chega-se à Ideia saindo da caverna das aparências, mas é preciso descer mais uma vez à caverna para iluminar aquilo que existe a partir da ideia. E é preciso fazê-lo, mesmo correndo certo número de riscos. 
Essa questão do retorno, eu a abordei uma primeira vez em $\mathrm{O}$ ser e 0 acontecimento (BADIOU, 1988), sob a denominação de "teoria do forçamento": força-se a transformação do saber comum a partir de uma nova verdade. É uma teoria bastante complexa, mas que, grosso modo, consiste em dizer que a verdade possui uma potência de modificação dos saberes, conforme sua disposição no mundo.

Quanto à Lógicas dos mundos (BADIOU, 2006), o livro não comporta uma teoria do forçamento, mas uma teoria das relações íntimas entre a singularidade do mundo e a universalidade de uma verdade, e isso através do fenômeno das condições concretas, em aparecimento, empíricas, da construção do corpo das verdades. Sustento que a verdade é um corpo. Assim, ela é feita do que existe, quer dizer, de outros corpos individuais, e é a isso que se dá o nome de incorporação. Essa incorporação nos esclarece a maneira pela qual uma verdade é disposta num mundo e a relação que ela tem com os materiais desse mundo, a saber, os corpos e a linguagem.

Em Lógicas dos mundos, eu parto da fórmula: "Em um mundo, só existem corpos e linguagens, exceto que existem verdades." Daí realizo um primeiro exame materialista desse "exceto que": as verdades são também corpos e linguagem, corpos subjetiváveis. Para esclarecer a relação entre as verdades, os corpos e as linguagens, utilizo uma noção equivalente àquela do forçamento em $\mathrm{O}$ ser e 0 acontecimento (1988), a saber, o conceito de compatibilidade. Um corpo de verdades é composto por elementos compatíveis, no sentido ao mesmo tempo técnico e elementar, de que eles se deixam dominar por um mesmo elemento.

No fundo, uma verdade é sempre uma multiplicidade unificada, dominada ou organizada por alguma coisa que torna compatível algo que não o seria necessariamente. Para dar um exemplo bastante simples: boa parte da concepção daquilo que seria um partido revolucionário consistiria em criar uma teoria em que intelectuais e operários fossem compatíveis, e onde a política tonasse compatíveis as diferenças de classe que em geral não o são. A teoria de Gramsci do intelectual orgânico, e outras teorias próximas, são desse tipo. Elas não tratam simplesmente de diferenças de classe tanto quanto de conflitos, criam também compatibilidades entre classes que não existiam, daí, por exemplo, uma teoria das alianças de classe. Em estética, tem-se uma situação da mesma ordem. Uma obra de arte - considerada como tema — cria compatibilidades entre coisas consideradas como não compatíveis, absolutamente distintas. Uma pintura se forma entre cores que não parecem destinadas a estar juntas, entre formas que seriam discrepantes. Ela integra formas e cores por compatibilidades de tipo superior.

Em resumo, o conceito de forçamento, no nível ontológico, e o conceito de compatibilidade, no nível fenomenológico, já abordam a relação entre a verdade e a situação na qual a verdade procede e, portanto, também, de maneira implícita, a nova dialética entre o finito e o infinito. O terceiro volume sistematizará tudo 
isso. De algum modo, ele se instalará a partir dos diferentes tipos de verdade para se perguntar: O que se passa quando um mundo todo é abordado do ponto de vista da verdade? O que se passa no nível ontológico quando se adota o ponto de vista das multiplicidades genéricas em relação às multiplicidades ordinárias, quaisquer que sejam, e compõem ontologicamente uma situação?

A construção desse livro futuro será, em suma, bastante simples. Devo fazer um grande desenvolvimento inaugural, mais técnico e mais preciso, do problema que acabo de apresentar de maneira pontual: o problema da relação entre os indivíduos incorporados por uma verdade e as multiplicidades ordinárias, pensadas tanto em seu ser quanto em seu aparecer mundano.

Essa introdução se organizará em torno de uma ideia muito simples, a saber, que a incorporação de uma verdade é invariavelmente uma nova forma de articular a dimensão finita dos indivíduos e a dimensão infinita de todo processo de verdade. O formalismo subjacente será, portanto, necessariamente uma nova dialética das multiplicidades finitas e das multiplicidades infinitas, tendo como suporte matemático a teoria moderna dos "infinitamente grandes".

Essa teoria é, segundo meu entender, uma condição essencial para toda a filosofia da dialética entre o infinito e o finito, por exemplo, pois ela é capaz de distinguir os infinitos fracos, que, na melhor das hipóteses, produzem apenas partes do saber, dos infinitos fortes, que acompanham o surgimento de uma verdade.

Devo fazer, em seguida, uma segunda parte que elucidará as leis gerais, os dispositivos formais, que organizam as relações com o mundo, a partir do ponto de vista das verdades. Assim, teremos uma teoria geral da incorporação individual e dos afetos que a sinalizam. Perguntaremos: o que é a iluminação do mundo do ponto de vista das verdades? O que é um obstáculo? Uma vitória? Um fracasso? Uma criação?

Uma terceira parte retomará as coisas por um procedimento da verdade, propondo uma teoria sistemática da arte, da ciência, do amor e da política. Tal teoria, mesmo tendo sido esboçada em diversas partes de minha obra, não é apresentada em lugar algum. Aí está o plano Ideal de $A$ imanência das verdades, em seu estado atual de work in progress.

O objetivo de tudo isso é vincular a noção de verdade à representação daquilo que é uma vida humana digna desse nome. O problema é, portanto, aquilo que chamo de "vida verdadeira".

A questão da vida, já abordei no final de Lógicas dos mundos (2006). O que é a vida verdadeira que Rimbaud diz estar ausente, mas que sustento estar presente? Minha resposta: é viver sob o signo da Ideia, quer dizer, viver sob o signo da incorporação efetiva das verdades. A última questão de $A$ imanência das verdades será vizinha, mas diferente: existirá uma Ideia das ideias, isto é, uma Ideia da vida 
completa? Voltamos, assim, à ambição da sabedoria antiga. Reencontramos essa aspiração inicial de uma vida não somente marcada pela Ideia e pela verdade, mas pela ideia de uma vida acabada, vida que teria experimentado, em matéria de verdade, tudo o que pode sê-lo.

Contudo, é preciso ir mais longe e se perguntar qual é a relação da filosofia com a vida. É uma questão primordial. Se não se pode dizer para que serve a filosofia do ponto de vista da vida verdadeira, ela permanece apenas uma disciplina acadêmica suplementar. O terceiro volume tentará, portanto, criar também a possibilidade de uma abordagem direta dessa questão. Tratar-se-á de retomar a questão platônica da relação entre a filosofia e a felicidade da vida.

Em suma, é preciso passar de uma doutrina negativa da singularidade universal das verdades para uma doutrina imanente e afirmativa. Eu mesmo me assusto com o fato de ter tratado o instante das verdades, e consequentemente o sujeito — o sujeito é o protocolo da orientação de uma verdade, verdade e sujeito estão absolutamente ligados — apenas de maneira diferencial. Perguntei a mim mesmo que tipo de multiplicidade é uma verdade. O que a diferencia de uma multiplicidade qualquer? Era a proposição central de $O$ ser e 0 acontecimento (1988). Já naquela época, portanto, eu estava na exceção. Se uma verdade é uma exceção às leis do mundo, deve ser possível explicar em que consiste essa exceção. Se se está no domínio da ontologia, da teoria do ser, da teoria matemática do ser, deve ser possível explicar matematicamente qual é o tipo de multiplicidade que singulariza as verdades.

Apoiando-me na teoria dos conjuntos e nos teoremas de Cohen, mostro que essa multiplicidade é genérica. Em outros termos, trata-se de uma multiplicidade que não se deixa pensar a partir dos saberes disponíveis. Predicado algum do saber disponível permite identificá-la. Para isso serve a técnica de Cohen: para mostrar que pode existir uma multiplicidade indiscernível, a qual não se deixa discernir pelos predicados que circulam nos saberes. Dessa forma, no nível de seu ser mesmo, a verdade escapa ao saber. Essa parece ser uma determinação positiva das verdades: elas são multiplicidades genéricas. Mas, se olharmos de perto, trata-se de uma determinação negativa: são as multiplicidades que não são redutíveis ao saber disponível. A minha definição de verdade, portanto, passa por uma abordagem diferencial e não por uma construção intrínseca ou imanente.

Em Lógicas dos mundos (2006), a verdade é definida como um corpo subjetivável. Quais são suas características próprias? Existem várias, mas uma é central: o protocolo de construção desse corpo é tal que tudo aquilo que ele compõe é compatível. Essa compatibilidade, todavia, não é, senão, no fundo, uma característica relacional do que é uma verdade. No interior da verdade, encontra-se uma relação de compatibilidade entre todos os seus elementos. É uma característica objetiva. Logo, nos dois casos, obtive uma determinação objetiva e 
precisa, respectivamente, do ser de uma verdade e do aparecer de uma verdade, com os conceitos de generalidade e de compatibilidade. Falta ainda, no entanto, precisamente, uma determinação subjetiva. Tudo isso nos diz apenas da verdade vívida a partir do interior do procedimento de verdade, isto é, do que ela é para o sujeito mesmo da verdade. Tudo isso não nos diz o que ocorre quando se subjetiva uma verdade.

Em Teoria do sujeito (1982), eu distinguia o "processo subjetivo" e a "subjetivação". Para manter essa distinção, eu diria que O ser e o acontecimento (1988) e Lógicas dos mundos (2006) contêm coisas decisivas sobre o "processo subjetivo", mas que a "subjetivação" permanece obscura, tratada negativamente e de maneira apenas diferencial. A subjetivação é a forma pela qual a gente se subjetiva a partir do interior do protocolo de verdade. Falta uma intuição daquilo que é uma subjetivação e, sobretudo, daquilo que podem ser, para uma mesma verdade, subjetivações diferentes.

Se os protocolos subjetivos de uma verdade se compõem por reuniões ou por incorporações de indivíduos ao devir de uma verdade, logo, a questão é de saber como funciona a diferença individualizada no interior do protocolo de verdade. Tomemos um exemplo bastante simples. Duas pessoas contemplam um quadro. Teremos um fragmento de incorporação, fragmento marcado por determinado afeto, um trabalho de inteligência, pela imobilização do olhar sobre o quadro. Coloco-me aqui mais na perspectiva do espectador que na do criador para indicar que uma verdade está constantemente disponível à incorporação.

Será que esse ato de subjetivação que corresponde à incorporação é idêntico para os dois espectadores? Trata-se de identidade ou de compatibilidade? Em todo caso, não se pode dizer que a dualidade que marca essa experiência — é possível, aliás, existirem milhões de pessoas nessa mesma experiência — irá romper a unidade do sujeito. Como isso se dá? Uma grande parte do ceticismo em relação ao que tange as verdades se enraíza nesse tipo de experiência. Cada qual com sua verdade, dizia Pirandello. "Cada qual com sua verdade" implica que não há a verdade de todos. No caso do quadro, haverá um único objeto que se deslocará conforme as percepções de alguns e de outros.

Agora, por que motivo esse problema da dispersão subjetivante diz respeito à negação? Porque a dificuldade é de saber a que tipo de negação faz referência essa dispersão. Cada um enxerga o quadro à sua maneira, a percepção de um não é a percepção de outro. Mas o que significa esse "não é”? O que perturba a percepção e conduz ao ceticismo é a ideia de que esse "não é” é uma negação clássica, isto é, que uma das percepções pode e deve ser contraditória em relação à outra.

Em qual teoria da negação podemos nos apoiar para, assim, evitarmos essa consequência cética da negação ordinária? A resposta é que devemos tomar como suporte a teoria da negação paraconsistente, um terceiro tipo de lógica (depois da 
clássica e da intuitiva), descoberto pelo brasileiro Da Costa, em que o princípio de contradição não tem validade. Assim, para além do uso detalhado da teoria dos infinitos, o novo formalismo, introduzido em grande escala nesse terceiro tomo, será o da negação paraconsistente, a qual contradiz de modo explícito o princípio da não contradição. Esse formalismo permite que, em se tratando de uma verdade, percepções contraditórias possam coexistir sem interromper sua unidade. Isso me interessa ainda mais, visto que na essência do amor se coloca um problema desse gênero - quando se admite, como é minha tese, que, para compreendê-lo por completo, deve-se partir da coexistência de uma posição feminina e de uma posição masculina, posições, a certos olhares, inteiramente disjuntas.

Se, portanto, o grande formalismo de O ser e o acontecimento (1988) foi a teoria dos conjuntos e a teoria de Cohen, e se o grande formalismo de Lógicas dos mundos (2006) foi a teoria dos feixes, a topologia, logo, de maneira ampla, a lógica intuitiva, o formalismo do terceiro volume será a promoção de uma articulação entre a teoria moderna dos infinitos e a lógica paraconsistente, com toda uma reflexão sobre os limites do princípio da não contradição.

Platão parte de uma experiência filosófica da Ideia, mas a necessidade de transmitir essa experiência permanece para ele exterior ao conteúdo propriamente dito da experiência. É por isso que ele afirma que seria preciso forçar os filósofos a se fazerem políticos e pedagogos. Quando eles tiverem sido conduzidos até a Ideia do Bem, terão apenas uma ideia - e fica nisso! Essa necessidade de transmitir, que vem de fora da experiência mesma da verdade, é para Platão uma exigência social e política. É preciso que essa experiência possa ser partilhada no âmbito da organização geral da sociedade. Se isso não é transmitido, deixa-se as pessoas sob o império das opiniões dominantes. É preciso, portanto, “corromper" a juventude, no sentido dado por Sócrates, isto é, transmitir a ela os meios de não ser escravizada pelas opiniões dominantes.

Partilho por inteiro essa visão da filosofia. Sou bastante vinculado, como se sabe, à sua didática. Mas é preciso reconhecer que em Platão há uma obscuridade quanto à questão de saber qual é a natureza da verdade. Essa verdade ele não a desvendou? verdadeiramente. Sabe-se que houve interpretações bem contraditórias a respeito de Platão. Ele pôde ser visto, por Galileu e por muitos outros, como o principal exemplo do racionalismo científico. Entre os neoplatônicos, todavia, foi tido como exemplo da teologia transcendente. Essas divergências se explicam pelo fato de Platão não ter dito muita coisa sobre essa verdade de que fala. De qualquer maneira, conservou dela a experiência. E talvez faltaria a ele, para ir mais longe, uma racionalização do conceito de infinito, de sua pluralização matemática, para a qual a humanidade teve que esperar por mais de dois milênios, de Eudoxo a Cantor. 
É bastante difícil, portanto, pensar o que é uma verdade sem poder dizer claramente que ela vem de um tipo de infinito diferente daquele no interior do qual opera, ou se constrói, e que o infinito verdadeiro não é o infinito que é. É também por isso que a teoria platônica da felicidade, justo em seu princípio (a felicidade é a subjetivação do verdadeiro), permanece abstrata quanto à sua possibilidade.

Para mim, as verdades existem, eu as caracterizo, disse e direi de maneira explícita como e por que elas existem. É verdade que a transmissão é aqui difícil. O que é preciso transmitir é que as verdades, já que existem, estão, em primeiro lugar, em exceção em relação ao restante, e que, em segundo lugar, elas existem enquanto obras, com base numa dialética estreita entre muitos tipos de infinitude. Platão, ele também, aliás, apresentou a Ideia do Bem como excepcionalidade.

A Ideia do Bem não é uma Ideia! Segundo uma passagem da República, bastante comentada, ela ultrapassa em muito, em prestígio e em potência, a Ideia. O que pode ser? A teologia negativa dirá que é Deus, e de Deus não se pode dizer nada. Do lado do racionalismo, encontramos a leitura de Monique Dixsaut e de muitos outros - a minha também, nesse caso. Ela consiste em mostrar que há um princípio de inteligibilidade que não é redutível à própria Ideia. Que a Ideia seja um princípio de inteligibilidade isso se situa naturalmente para além da Ideia entendida como princípio regional de ação ou de criação. Sem dúvida, Platão ainda não tinha os meios - infinitos de tipo superior e lógica paraconsistente - de conceitualizar esse "para além".

No fundo, pode-se dizer que persigo, de uma ponta a outra de minha empreitada filosófica - de Teoria do sujeito (1982), há 33 anos, ao futuro, A imanência das verdades - uma reflexão sobre a verdade que está ligada de maneira bastante estreita à questão da negação. Busco, pura e simplesmente, dar uma razão à possibilidade da mudança, à possibilidade de passar de um certo regime de leis do que é para um outro regime, pela mediação do protocolo de uma verdade e de seu sujeito.

Estou, portanto, numa teoria dialética da verdade que utiliza, se for o caso, uma negação paraconsistente da finitude por um infinito completo. Mas como meu pensamento dialético inclui a figura de um acaso, ele é não determinista. Lembro que a dialética hegeliana é implacavelmente determinista. Nisso ela é um grande pensamento, típico do século XIX. É o espetáculo do autodesenvolvimento do Absoluto na necessidade imanente desse desenvolvimento.

Estou, claro, muito longe de tudo isso. É a razão pela qual tenho com Hegel uma relação estreita e complicada, ao mesmo tempo. Não se deve esquecer que nos meus três grandes livros já publicados Hegel é um autor minunciosamente discutido: em Teoria do sujeito (1982), a propósito do processo dialético em si, em O ser e acontecimento (1988), a propósito do infinito, em Lógicas dos mundos (2006), a 
propósito do ser-aí, das categorias do ser-aí. Em $A$ imanência das verdades, discutirei, de maneira central, o conceito hegeliano de Absoluto, pois, em definitivo, para mim, como para Hegel ou Platão, toda a verdade, toda a subjetivação na verdade, é um tipo de acesso provisório ao Absoluto. Apenas, nossas ideias sobre a questão não são as mesmas.

Sempre tive, portanto, uma discussão particular com Hegel, mas também com Marx, Lênin, Mao, os grandes revolucionários dialéticos, a propósito da condição política. Simplesmente, com a presença de um elemento aleatório, introduzi um princípio de ruptura que não é exatamente homogêneo aos princípios clássicos da negação. É por isso que, por fim, utilizarei três lógicas diferentes e entrecruzadas: a lógica clássica, a lógica intuitiva e a lógica paraconsistente. Ao mesmo tempo, elevarei ao absoluto o referencial ontológico — o pensamento do múltiplo puro - com a introdução da teoria, de fato sensacional, dos “infinitamente grandes". A triplicidade lógica e a infinitude dos infinitos serão a chave de uma teoria geral da vida verdadeira, ou da vida em verdade, que é o objetivo de toda filosofia.

Para mim, a filosofia é essa disciplina de pensamento, essa disciplina singular, que parte da convicção de que existem verdades. Daí ela ser conduzida a um imperativo, uma visão da vida. Qual é essa visão? O que tem valor para um ser humano, o que lhe concede uma vida verdadeira e orienta sua existência, é ter parte com essas verdades. Isso supõe a construção, bastante complexa, de um aparelho para discernir verdades, aparelho que permite circular entre elas, permitindo possibilitá-las. Tudo isso levando em conta a contemporaneidade.

A filosofia é essa trajetória. Vai, portanto, da vida, que propõe a existência de verdades, até a vida que faz dessa existência um princípio, uma norma, uma experiência. O que a época em que vivemos nos oferece? O que ela é? Quais são as coisas que nela têm valor? Quais são as coisas não nela não têm valor? A filosofia propõe uma seleção na confusão da experiência, a partir da qual tira uma orientação. Essa ascensão da confusão à orientação é a operação filosófica por excelência e sua dialética própria.

Isso supõe um conceito da verdade. Essa "verdade" pode muito bem receber outro nome. Logo, por toda parte na obra de Deleuze, o que chamamos aqui de "verdade" é chamado de "sentido". Posso identificar, em qualquer filosofia, o que eu mesmo nomearia por "verdade”. Isso pode ser nomeado por “Bem”, “espírito”, “força ativa”, “númeno”... Eu escolhi "verdade”, porque assumo o classicismo.

É preciso, portanto, uma seleção e, para isso, é preciso uma máquina de selecionar, isto é, um conceito de verdade. É preciso mostrar que essa verdade existe verdadeiramente, mas que nisso não há milagre algum e que não é necessário ter dispositivos transcendentes. Algumas filosofias têm esses dispositivos. Mas essa não é de modo algum a minha via. Logo, voltamos para a questão simples, 
questão inicial: o que é viver? O que é uma vida digna e intensa que não pode ser reduzida a parâmetros estritamente animais? Uma vida que sinaliza o afeto que está aqui em questão, o afeto da felicidade real?

Penso que a filosofia deve incluir, ao mesmo tempo, em sua concepção e em sua proposição, a convicção de que a vida verdadeira pode ser experimentada em imanência. Alguma coisa deve sinalizar a vida verdadeira no interior, não apenas como um imperativo exterior, como um imperativo kantiano. Isso vem de um afeto que sinaliza, indica, em imanência, que a vida vale a pena ser vivida. Há em Aristóteles uma fórmula que gosto muito e que retomo de bom grado: "Viver na imortalidade". Há outros nomes para esse afeto: "beatitude”, em Espinosa, "alegria”, em Pascal, "super-homem”, em Nietzsche, "santidade”, em Bergson, "respeito", em Kant... Creio que há um afeto da vida verdadeira e dou a ele o nome mais simples, o de felicidade. Esse afeto não tem componentes sacrificiais. Nada de negativo é exigido. Não há nele, como nas religiões, sacrifício cuja recompensa está alhures e para amanhã. Esse afeto é o sentimento afirmativo de uma expansão do indivíduo, uma vez que ele coparticipa do sujeito de uma verdade.

Entendi muito recentemente a inacreditável obstinação de Platão em demonstrar que o filósofo é feliz. O filósofo é o mais feliz em relação a todos que cremos serem mais felizes do que ele: os ricos, os hedonistas, os tiranos... Platão nos propõe inúmeras demonstrações para este ponto: só é verdadeiramente feliz aquele que vive sob o signo da Ideia, e esse é o mais feliz de todos. O que isso significa é evidente: o filósofo experimentará, no interior de sua vida, o que é a vida verdadeira.

A filosofia é, portanto, três coisas. É um diagnóstico da época: o que a época propõe? É uma construção, a partir dessa proposição contemporânea, de um conceito de verdade. É, enfim, uma experiência existencial relativa à vida verdadeira. A unidade das três é a filosofia. Mas, em dado momento, a filosofia é uma filosofia. Quando eu tiver escrito $A$ imanência das verdades, tendo assim de fato proposto a unidade dos três componentes de toda a filosofia, poderei dizer: a filosofia sou eu. E é, portanto, da mesma forma e de igual modo, com todos vocês, que me leem e que pensam comigo nisso ou contra mim, tanto faz. Pois se existe pensamento, existe também a eternidade de uma experiência terrena, a imanência de uma vida verdadeira. Logo, todos nós, amigos e inimigos, partilharemos a felicidade dessa imanência.

Recebido em 27/6/2015. Aprovado em 6/7/2015. 


\title{
REFERÊNCIAS
}

BADIOU, A. (1982). Théorie du sujet. Paris: Seuil.

(1988). L'être et l'événement. Paris: Seuil.

(2006). Logiques des mondes: l'être et l'événement 2. Paris: Seuil.

\author{
Alain Badiou \\ inbadiou4@gmail.com \\ Luiz Paulo Leitão Martins \\ lplmartins@gmail.com
}

